$£ 50$ per pound of pure metal would be sufficient to mine and to refine sufficient uranium to provide the world's present energy requirements for some 1,500 years, or on a similar basis, an expenditure of $£ 100$ per pound could furnish these requirements for 8,500 years. The abundance of hydrogen in the earth's crust could provide almost unlimited power from the hydrogen-helium reaction, but the industrial application of this must await the discovery of means of enabling the reaction to proceed at a lower sustained temperature.

Because of the possibility of supplying the world demand for power by means of nuclear fission, it is now sometimes argued that all development effort should be applied in that direction and the development of other sources abandoned. Mr. Eccles, however, did not hold this view : when there is, for example, "a local surplus of water power, the energy could be used to purify fissile material so as to provide power in lands where the alternatives are insufficient. Since fissile material, even in its natural state, is easily transportable, such packaged fuel might solve the power transmission problem".

Finally, Mr. Eccles referred to the minute fraction of existence of the human race within which this tremendous demand for power has developed, and he emphasized the paramount necessity to match, by means of continued technological advancement, the world's progressive demands for the basic necessities of food and fuel. "In sum, therefore, man having evolved during a million years has, over the past 250 years, developed a mode of living which is unique in human history. This achievement has thus lasted for only 0.025 per cent of his sojourn here and already it has made great demand on the energy resources of our planet. Unless he is able and willing to match his technology to the unfolding needs of the situation, he has no prescriptive right to a continuance of this latest civilization, and the history of civilizations discloses that discontinuitydecay and rebirth-is the normal method by which successive stages have been reached. However, to-day man is equipped with a knowledge of natural laws (science) and an ability to harness these laws to his needs (engineering) that were absent in all previous civilizations, and there is good reason for thinking that the present mode of living can be greatly prolonged if he will but use this knowledge and abjlity aright."

\section{AIRCRAFT ELECTRICAL SYSTEMS}

VACATION school on "Aircraft Electrical
Systems" was held in the Electrical Engineering
Tepartment of the Imperial College of Science and
wechnology, London, during September $20-24$ and
was attended by nearly seventy engineers drawn
from electrical and aircraft industries, research
organizations and the College of Aeronatics, Cran-
field. The purpose of the school was to bring out
the scientific principles underlying the design and
application of all forms of equipment used in aircraft
electrical systems, in relation to both present and
future requirements. The course was very successful,
particularly since those who participated contributed
a large part to the discussions. The conclusions
drawn were that more co-operation is needed between
design and instaillation engineers and that, notwith.
standing the special conditions of aircraft work, much can be learned from ordinary industrial practice; educational work was also stressed, particularly the part being played by Imperial College.

In his opening address, Sir Frederick Handley Page emphasized the importance of fundamental research in that it often leads ultimately to useful practical results. After directing attention to electrical and aeronautical engineering as the two newest branches of the art, he referred to the interesting problems which have arisen as they have progressively come together, and to the need for closer liaison between members of these two branches. In an introductory survey, D. F. Welch (British Thomson-Houston Co., Coventry) outlined the problems facing the aircraft electrical engineer. Since 1940 power requirements have risen from $1 \mathrm{~kW}$. to $200 \mathrm{~kW}$. for large aircraft, and with these powers the potentially destructive power of a fault has focused fresh attention on circuit protection. The avoidance of any breakdown is doubly important in that the introduction of power-operated controls and the electrical operation of essential flying instruments mean that the safety of an aircraft is now dependent on the maintenance of the electrical power supply. M. Hancock (Royal Aircraft Establishment, Farnborough), speaking on environmental conditions and functional requirements, pointed out that these lead to acute differences between aireraft and groundbased electrical engineering practice: operation at high altitude increases arcing problems in switchgear and decreases machine cooling, while the wide temperature-range over which the equipment must function increases insulation and lubrication problems. Mechanical problems, vibration, weight and bulk considerations are all factors with special problems in relation to aircraft. In the third lecture, J. H. Rea (Rotax, Ltd.) dealt with power systems, and discussed the factors which determine the choice of system, methods of load analysis which distinguish between 'safety' and 'comfort' loads, and methods of weight analysis which lead to the lightest installation capable of supplying the load. The place of the battery, with particular reference to the problem of engine starting, was also considered.

The more specialized lectures given at the course commenced with that of R. F. Sims (Farnborough), who first discussed the physical causes of the abnormal brushwear experienced at high altitudes, outlining remedial measures such as the use of special materials or the control of the moisture content of the machinecooling air, and then in the second part of his lecture considered vibration problemis. After a general survey of cooling problems, Dr. C. S. Hudson (Farnborough) reviewed the effects of radiation, natural and forced convection, and conduction, and discussed methods of calculating the pressure head required in a cooling system. The topic of d.c. machines was covered in the next lecture by $B$. Adkins (Imperial College, London), who showed how machines must be compactly constructed in order to obtain the output required with minimum weight. He also pointed out how the insulation, the methods of connecting and securing the windings, and the grease used for lubrication, all set a limit to the permissible temperature rise.

On September 22 the members of the course visited the works of Vickers-Armstrong, Ltd., at Weybridge, including the company's Electrical Laboratory and the Research Department, and the seventh lecture, on electrical installation engineering, by H. Zeffert (Vickers-Armstrong), was partly a com- 
mentary on the visit, for Dr. Zeffert described and demonstrated many types of plugs, sockets, terminal blocks and cables. The main run of lectures was continued on the next day with one on a.c. machines by W. Philipp (Rotax, Ltd.), who discussed the problems of alternator design, both for the long speed-range machines now in use and for the constant-speed machines which will be required when a constant-speed drive, taken either from an enginedriven hydraulic gear or from a separate turbine, becomes available; he also spoke on conversion equipmont, using invertors, rotary transformer or motor-alternators, and on induction motors. From machines the programme of the course turned to system operation and protection; in which $\mathrm{K}$. J. Payne (British Thomson-Houston Co., Coventry) considered power system maintenance, servicing the system or correcting faults being, of course, impossible during actual operational use. After a general discussion on the limits of operation of the components of a typical system and their effects on system performance, and also protection techniques, Mr. Payne described the transient behaviour of inverters and motors and the effects of electrical and mechanical shock loads. The theme of A. Grieve's (British Thomson-Houston Co., Coventry) lecture was switchgear, the factors involved in the design of switches, and the limitations imposed on performance by the fundamental properties of the matcrials and of the environment in which they are to operate ; in discussing the characteristics required of a circuit breaker, he said that protection against most forms of fault can be incorporated in any unit of switchgear.

In the concluding survey, in which he discussed future trends, S. F. Follett (Ministry of Supply) stated that future aircraft will fly faster and higher, so that environmental changes will most influence future practice; he felt that the need for reliability should be stressed, and that reliability should bo proved on life-tests which approximate to aircraft conditions and allow for the effect of vibration.

\section{MARINE BIOLOGY IN LATIN AMERICA}

$\mathrm{D}$

URING September 15-17 a group of Latin American specialists in marine biology met in Concepción (Chile) in order to study the possibility of establishing an international network of marine biologieal laboratories in Latin America and other ways of facilitating the collaboration in this field among the Latin American countries. The meeting was convoked by the Unesco Science Co-operation Office for Latin America and was a sequel to the recommendations for setting up international and regional laboratories made at a meeting held in Montevideo in 1952 upon the initiative of the Unesco Office (see Nature, 170,$605 ; 1952$ ). The scientists attending the meeting were from the Argentine, Brazil, Chile, Cuba, Mexico, Peru, Venezuela and Uruguay, The Regional Office in Santiago de Chile of the United Nations Food and Agriculture Organization collaborated in arranging the meoting.

After studying the present situation of research in marine biology in Latin America and its future possibilities, the delegates entered on an extensive discussion about the possibilities and ways of establishing an international network of laboratories. It was unanimously decided to create immediately under the auspices of the Unesco Science Co-operation Office a Latin American Committee in order to co-ordinate and facilitate the research work in marine biology. The Committee would remain in office until a permanent organization had been set up. The meeting requested the Unesco Office to prepare $a$ draft convention for an international network of laboratories and convoke a meeting of official delegates in order to establish the corresponding organization.

The meeting also studied what other steps could bo taken immediately pending the realization of the more far-reaching recommendations, in order to promote research in marine biology, and advised the Unesco Office that two training-courses on the methodology of marine biology research and a symposium on plankton should be organized in 1955 . It was also recommended that the Marine Biology Journal, produced by the Montemar Station in. Chile, should be widened in scope with a Latin American editorial board.

The Brazilian representatives to the meeting have been duly authorized by the Governor of the State of São Paulo to put at the disposal of the Unesco Science Co-operation Office for international research work the complete network of marine biological laboratories and stations and research vessels of the State of São Paulo. 'This offer will make it possible to initiate shortly international research and training programmes in marine biology under the auspices of the Unesco Office.

\section{UNITED NATIONS ORGANIZATION}

\section{ANNUAL REPORT OF THE SECRETARY- GENERAL FOR 1953-54}

$T$

HE ninth annual report of the Secretary-General of the United Nations to the Member States on the work of the Organization during July 1, 1953June 30, 1954* is not an encouraging document. It gives a picture of diversity of effort which closely matches that to be found in the reports on the work of the League of Nations, and, as with that organization, it is in the technical fields that progress is most marked. Filsewhere, and above all in the political field, the gap between purpose and achieve. ment is wide; nor does it appear that all Member States are coneerned to advance the declared purposes of the United Nations. The Secretary-General comments on the need for a careful balance in the development of regional arrangements outside the framework of the United Nations. Choice of such arrangements for the maintenance of peace should not be permitted to cast doubt on the ultimate responsibility of the United Nations, or to impair the right of a Member State to a hearing under the Charter.

Referring to the lack of progress in disarmament, the Secretary-General comments on the potentialities of the development of an international partnership, open to all nations, in the use of atomic energy for peaceful purposes, especially for the economically

* United Nations. Annual Report of the Secretary-General on the Work of the Organization, 1 July 1953-30 June 1954. (Genera Assembly-Official Records: Ninth Session. Supplement No. 1 (A/2663).) Pp. xv +120. (New York: United Nations; London H.M.S.O., 1954.) 1.25 dollars; 98 .; 5 Swiss francs. 